\title{
INSTRUCTIONS FOR AUTHORS
}

The journal Contributions, Section of Natural, Mathematical and Biotechnical Sciences is an official publication of the Macedonian Academy of Sciences and Arts. It is published twice a year. The journal publishes original scientific papers, short communications, reviews, professional papers and educational papers from all fields of:

natural sciences - physics, chemistry, biology, geography, geology;

mathematical sciences - mathematics, informatics;

biotechnical sciences - agriculture and food, forestry.

This journal also publishes, continuously or occasionally, the bibliographies of the members of the Macedonian Academy of Sciences and Arts, book reviews, reports on meetings, information on future meetings, important events and dates, and various headings which contribute to the development of the corresponding scientific field.

The original scientific papers report unpublished results of completed original scientific research. Experimental data should be presented in a way that enables reproduction and verification of analyses and deductions on which the conclusions are based. The manuscripts should normally not exceed 6000 words.

The short communications should contain completed (but briefly presented) results of original scientific research. The manuscripts should normally not exceed 2000 words.

The reviews are submitted at the invitation of the Editorial Board. They should be critical surveys of an area in which preferably the author himself is active. The reviews can be longer than typical research articles but should generally be limited to 10000 words including references, tables and figures.

The professional papers report on useful practical results that are not original but help the results of the original scientific research to be adopted into scientific and production use. Manuscripts should normally not exceed 4000 words.

The educational papers report on the activities in the laboratory and classroom and the needs of the community of educators in all mentioned fields. Manuscripts should normally not exceed 4000 words.

\section{Submission of manuscripts}

The authors bear the sole responsibility for the content of the contributions. It is assumed that by submitting their paper the authors have not violated any internal rules or regulations of their institutions related to the content of the contributions. Submission of a paper implies that it has not been published previously, that it is not under consideration for publication elsewhere, and that, if accepted, will not be published elsewhere in the same form, in English or in any other language, without the written consent of the Publisher.

A cover letter must accompany the manuscript submission. It should contain full names of all authors and their affiliation, the manuscript title and the name and contact information for the corresponding author. Please provide e-mail address and phone number. For submission, please send an electronic version of the manuscript (in MS Word) at: smalinovska@manu.edu.mk

\section{Preparation of manuscripts}

Prepare the entire manuscript in double-space typing, on numbered pages of A4 format with margins of $2.5 \mathrm{~cm}$ on each side. Do not use footnotes.

The papers should be written in the shortest possible way and without unnecessary repetition. The original scientific papers, short communications, professional papers and reviews should be written in English. An Abstract and list of key words in Macedonian must accompany each manuscript. For contributions by authors who are not speakers of Macedonian, the above data will be provided by the Editorial Board.

The manuscript should contain: title, authors names and addresses, abstract, key words, introduction, experimental or theoretical background, results and discussion, acknowledgement (if desired) and references.

Title. It should be brief and informative but should define the subject of the manuscript. It should include most of the key words.

Authorship. List the first and last name of each author. Omit professional and official titles. Give the complete mailing address of each author. For the corresponding author include an e-mail address and a phone number. The name of the corresponding author should carry an asterisk. 
Abstract. Each manuscript should be provided with an abstract of about 100-150 words. It should give the aim of the research, methods or procedures, significant results and conclusions. Define any abbreviations used in the abstract. The text of the abstract should contain as many key words as possible. searching.

Key words. Up to $5 \mathrm{key}$ words or phrases should be given separately to facilitate indexing and on-line

Introduction. The most important previous results related to the problem in hand should be reviewed avoiding a detailed literature survey but clearly pointing to the place of the research in hand within the general area of scientific knowledge. The aim and importance of the research should be clearly stated.

Experimental section. This section should contain a description of the materials used and methods employed in form which makes the results reproducible, but without detailed description of already known methods.

Manuscripts that are related to theoretical studies, instead of experimental section should contain a subheading theoretical background where the necessary details for verifying the results obtained should be stated.

Results and discussion. The authors should discuss their findings, postulate explanations for the data, elucidate models and compare their results with those of other works. Irrelevant comparisons and speculations unsupported by the new information presented in the manuscript should be avoided. The conclusions should be not given separately but included in this section. In special cases a separate section containing conclusions could be included.

Tables. They should be given with a suitable caption and should be numbered consecutively with Arabic numerals. Footnotes to tables should be typed below the table and should be referred to by superscript lowercase letter. Each table should be typed on a separate sheet. The correct position of the tables should be marked on the manuscript.

Figures. Figures (photographs, diagrams and schemes) should be numbered consecutively with Arabic numerals in order to which they mentioned in the text. They should accompany the manuscript but should not be imbedded in the text. Each figure should be clearly marked with the figure number and the first author's name. All figures should have captions that should be supplied on a separate sheet. Correct position of the figures should be marked on the manuscript. The size of the symbols for the physical quantities and units as well as the size of the numbers and letters used in the reduced figures should be comparable with the size of the letters in the main text of the paper. Each figure or group of figures should be planned to fit, after appropriate reduction, into the area of either one or two columns of text. The maximum finished size of a one-column illustration is $8.0 \mathrm{~cm}$ and that of a twocolumn illustration is $17.0 \mathrm{~cm}$ width. Make sure you use uniform lettering and sizing of your original artwork. All figures should be printed on a high quality printer or graphics plotter. Figures should be also sent in electronic form as TIFF or JPG files with minimum 300 dpi or higher resolution.

Color illustrations in print can be included only at the author's expense.

Units. The SI (Systeme Internationale d'Unites) for quantities and units should be used throughout the whole text. In marking the axes, the symbol, of the corresponding quantity (in italics) should be divided by the unit of this quantity. If nomenclature is specialized, nomenclature section should be included at the end of the manuscript, giving definitions and dimensions for all terms.

The names of chemical substances should be in accordance with the IUPAC recommendations and rules or Chemical Abstract practice.

The results of elemental analyses of organic compounds should be given in the following form:

Anal. $\mathrm{C}_{12} \mathrm{H}_{16} \mathrm{O}(176.26)$.

Calc'd: C 81.77; H 9.15; O $9.08 \%$.

Found: C 81.63; H 9.36; O $9.01 \%$

When a large number of compounds have been analyzed, the results should be given in tabular form.

Formulas and equations. Chemical equations should be balanced and numbered consecutively along with mathematical equations or other mathematical expressions. All of them should be marked with Arabic numerals in parenthesis in the right hand margin. The use of equation editor (Word) for typesetting the equations is recommended. Strokes (/) should not be used instead of parentheses.

Acknowledgement. Financial support, advice or other kinds of assistance can be included in this section.

References. Literature references should be numbered and listed in order of citation in the text. They should be selective rather than extensive with the exemption to review articles. Avoid references to works that have not been peered-reviewed. Citation of a reference as "in press" implies that it has been accepted for publication. Abbreviations of the titles must follow the internationally accepted practice.

The surname (not first name and/or initials) of one or two authors may be given in the text, whereas in case of more than two authors they should be quoted as, for example, Julg et al. [1]. In the list of references the citation should be as follows: 
Journals:

[1] J. Zhang, X. Wang, H. Xie, Phonon energy inversion in graphene during transient thermal transport, Phys. Lett. A, 377 (2013), pp. 721-726.

[2] G. Jovanovski, P. Makreski, B. Šoptrajanov, B. Kaitner, B. Boev, Minerals from Macedonia, Contributions, Sec. Math. Tech. Sci., MANU, XXVI, 1 (2005), pp. 7-84.

[3] A. Čarni, M. Kostadinovski, V. Matevski, Species composition and syntaxonomic consideration of two communities of the Drabo-Cardaminion hirsutae in the southern part of the Republic of Macedonia, Acta Bot. Croat., 62 (2003), pp. 47-56.

[4] D. Dimovski, A geometric proof that boundary links are homotopically trivial, Topology Appl., 29 (1988), pp. 237-244.

[5] F. C. Oliveira, Á. C. Collado, L. F. C. Leite, Autonomy and sustainability: An integrated analysis of the development of new approaches to agrosystem management in family-based farming in Carnaubais Territory, Piauí, Brazil, Agr. Syst., 115 (2013), pp. 1-9.

Books:

[1] J. A. Roels, Energetics and Kinetics in Biotechnology, Elsevier Biomedical Press, Amsterdam, New York, Oxford, 1983.

[2] H. Chum, M. Baizer, The Electrochemistry of Biomass and Derived Materials, ACS Monograph 183, American Chemical Society, Washington, DC, 1985, pp. 134-157.

[3] J. W. Finley, G. A. Leveille, Macronutrient substitutes, in: Present Knowledge in Nutrition, E. K. Ziegler, L. J. Filer Jr. (Eds), ILSI Press, Washington DC, 1996, pp. 581-595.

[4] Gj. Filipovski: Characteristic of the Climatic and Vegetational Soil Zones in the Republic of Macedonia, Macedonian Academy of Sciences and Arts, Skopje, 1996.

Scientific meetings:

[1] M. S. Steel, Creating woodlands for wildlife and people in Scotland, $18^{\text {th }}$ Commonwealth Forestry Conference; Restoring the Commonwealth's Forests: Tackling Climate Change, Edinburgh, Scotland, 2010, Book of Abstracts, p. 3.

Note that the full titles of the cited papers should be included.

For the web references, as a minimum the full URL should be given. Any further information, if available (author names, dates, reference to a source publication, etc.) should also be given.

\section{Editorial process}

Receipt of manuscripts. The received manuscript is read and examined for conformity to these Instructions to Authors. Failure to meet the criteria outlined will result in return of the manuscript for correction before evaluation.

Peer review/evaluation. Papers received by the Editorial Board are sent to two referees (one in the case of professional and educational papers). Identities of the reviewers will not be released to the authors. The review process is expected to be complete within 3 months, but conflicting recommendations and other unpredictable events may cause some delay.

The comments and recommendations of the referees and the Editorial Board are sent to the authors for further action. The authors are allowed 30 days to undertake revisions and return the corrected text to the Editorial Board. The final decision on acceptance or rejection is made by the Editorial Board. This decision, together with any relevant reasons, will be send to the corresponding author.

Publication process. The accepted manuscript is again checked for conformation to the Instructions to Authors and to ensure that all necessary paperwork is present. Any areas that are identified as problematic will be addressed by the Editorial Board in consultation with the corresponding author. The papers will be prepared for publication by a professional copy editor responsible for ensuring that the final printed work is consistent in form and style.

Galley proofs. A galley proof is sent to the corresponding author. It should be checked very carefully and must be returned within 2 days of receipt. The proof stage is not the time to make extensive corrections, additions, or deletions.

Reprints. The corresponding author will receive, free of charge, 20 reprints of the paper published in the Contributions. Additionally he will receive a complementary copy of the journal. 